NOTICE WARNING CONCERNING COPYRIGHT RESTRICTIONS:

The copyright law of the United States (title 17, U.S. Code) governs the making of photocopies or other reproductions of copyrighted material. Any copying of this document without permission of its author may be prohibited by law. 
University Libraries Carnegie Mellon University

Pittsburgh PA 15213-3890

\title{
DUNCKER ON THINKING: An Inquiry into Progress in Cognition
}

\author{
Allen Newell \\ December 1980
}

\section{Department of Computer Science \\ Carnegie-Mellon University Pittsburgh, Pennsylvania 15213}

\author{
To appear in: Sigmund Koch and David Leary (Eds.), \\ A Century of Psychology as Science: \\ Retrospections and Assessments, \\ New York: McGraw-Hill (forthcoming)
}

This research was sponsored by the Defense Advanced Research Projects Agency (DOD), ARPA Order No. 3597, monitored by the Air Force Avionics Laboratory Under Contract F33615-78-C-1551.

The views and conclusions contained in this document are those of the authors and should not be interpreted as representing the official policies, either expressed or implied, of the Defense Advanced Research Projects Agency or the US Government. 


\section{Table of Contents}

1. INTRODUCTION

2. THE HISTORICAL CONTEXT

2.1. A Hundred Years of Cognition

2.2. Duncker

2.3. The Cognitive Revolution

3. THE STRUCTURE AND DYNAMICS OF THE PROBLEM SOLVING PROCESS

3.1. What Duncker Knew

3.2. What We Now Know

4. INSIGHT, LEARNING AND SIMPLE FINDING

4.1. An Alternative View

4.2. A Computational Model of Insight

4.3. Other Mechanisms

4.4. Limitations

5. FIXEDNESS OF THOUGHT-MATERIAL

5.1. What Duncker Knew

5.2. Why Psychology took up Functional Fixity

5.3. The Position of Modern Cognition

6. CONCLUSION

7. REFERENCES
3

3

5

5

8

8

\section{2}


PAGE II

\section{List of Figures}

Figure 2:1: Key events in one hundred years of the study of cognition. Figure 4-1: Duncker's computational model of insight. 


\section{DUNCKER ON THINKING: An Inquiry into Progress in Cognition}

\section{INTRODUCTION}

How to cast light on what we have learned about cognition in the last 100 years? It seems a pleasant enough task, as part of the American Psychological Association's centenary celebration of the establishment of Wundt's Laboratory in Leipzig. Yet, though initially pleasant to accept and contemplate, and also pleasant in the final delivery; difficulties arise in bridging the gap between the acceptance and the delivery -- a gap that arises for this as for every other genuine cognitive problem.

Cognition is only a part of Psychology and for much of the century a minor part. This derives from a larger history -- of how associationism and then behaviorism gave a particular cast to the study of the mind, how that cast emphasized learning, how the reactions to that, especially Gestalt psychology, found their main ground in perception. All this is oft recounted. The last quarter of this century has witnessed the return of the oppressed to a position of prominence. There is a story to tell about this revolution, though it too is generally familiar in its major outlines. But science celebrates its history, not by recounting it, but by critical appraisal. The task is to find out what we have learned.

My solution is to consider a particular scientist, Karl Duncker, and indeed a particular work, Zur Psychologie des produktiven Denkens, originally published in 1935 and translated as On Problem Solving in 1945 as a Psychological Monograph. Duncker studied how human adults solved various mathematical and practical problems. The most well known is the X-ray problem: How can a beam that destroys all tissue, healthy and diseased alike, be used to destroy only a tumor, sparing the healthy tissue. Duncker used thinking-aloud protocols as a source of data, analyzing in detail the processes that his subjects went through and how the solutions they found (or failed to find) reflected the structure of the task. The concept of functional fixity, familiar to all psychology students (at least to a decade ago) originated in this study.

What have we learned since Duncker? What did he know and what were his scientific tasks? What does cognition know now and where does it stand on Duncker's tasks?

This certainly transforms an open and unstructured task of how to deal with the whole of the history of cognitive psychology into a closed and manageable one. The solution, no doubt, appears sudden. How did I ever think of doing this?

In fact, the thought came a long time ago. I do not recall exactly when I first read Duncker, 
PAGE 2

sometime in the late fifties. ${ }^{1}$ Having had no formal training at all in Psychology, I was exploring what was already known, as my interests deepened in problem solving and cognition. Duncker made a strong impression on me. I noted then that Duncker would make an interesting topic for a paper, one that would be at once an appreciation and a critique. Now, in 1979, the opportunity has arisen and I have seized it.

In consequence, my first obligation is to put Duncker into his historical place, so you see why this choice of mine is appropriate to understanding what we have learned about cognition, over and above being a working out of my own personal agenda.

${ }^{1}$ After the work on the Logic Theorist program (Newell, Shaw \& Simon, 1958) (which did not cite Duncker, though we knew of him), while working on GPS (the General Problem Solver) (Newell, Shaw, \& Simon, 1960), though after GPS was created (Newell, Shaw \& Simon, 1957). 


\section{THE HISTORICAL CONTEXT}

\subsection{A Hundred Years of Cognition}

The hundred year time line is layed out in Figure 2-1. Duncker (1935b) occurs at about the halfway mark in the century, bracketed by its direct predecessor (Duncker, 1926), his master's thesis at Clark, and by the translation to English (Duncker, 1945). Duncker was a student of Max Wertheimer and Wolfgang Kohler; he dedicates his work to them jointly. This monograph reports essentially the only research Duncker did on problem solving, his other work being mostly in perception. This may have been because he died early, in 1940 when he was only 37 (he was then at Swarthmore with Kohler). In any event, our inquiry can be neatly localized to this one work.

The great cluster of events that occurs in the second half of the fifties, above the line signifies the start of the shift to an information processing viewpoint ... the start of the revolution in cognition. It can be seen in the variety of different strands -- Broadbent, Miller, Bruner-Goodnow-Austin, Chomsky, Swets-Tanner, etc. All were generated out of a rapidly shifting conceptual base growing out of the development of communications and computer technology, plus the mathematics of systems, as in game theory and operations research. The confluence of these strands, each distinct in many ways -their unity in diversity, to use a well worn phrase .- produced a conceptual explosion. We have documented our assessment of this critical period (Newell \& Simon, 1972); recently a short note by George Miller agrees (Mi!ler, 1979).

"What have we learned in cognition?", must have as a primary sense, "What has this shift to the information processing paradigm wrought in comparison to what we knew before?"

Three textbooks on thinking, written just before the '58 tsunami (Humphrey, 1951, Vinacke, 1952, Johnson, 1955), provide a neat fix on what had been learned to that point. ${ }^{2}$ They show that the work of Duncker was indeed an important and accepted component of the then current view of thinking. The "then current view" was not exactly coherent. With due regards to their authors, these books make dull reading, providing a congeries of assorted experimental facts, tenuously related theoretical ideas and historical notes on different schools. Duncker's work resides as one thread among many.

\footnotetext{
${ }^{2}$ These authors have each written a book on thinking well alter the shift to an information processing viewpoint (Humphrey \& Coxon, 1963, Johnson, 1972, Vinacke, 1974). These provide lovely data on the extent to which new paradigms are universally perceived and taken up. It is barely apparent in these tater works that anything specifically of an information processing nature has happened, though both Johnson and Vinacke speak in terms of the explosion of work on thinking and problem solving.
} 
PAGE 4

1880's

1890's James, Principles of Psychology, 1890.

Thorndike, Animal Intelligence, 1898.

1900's

1910's Dewey, How We Think, 1910.

Selz, Zur Psychologie des produktiven Denkens und des Irrtums, 1922 (1913).

1920's Kohler, The Mentality of Apes, 1925 (1917).

Duncker, A qualitative study of productive thinking, 1926.

Maier, Reasoning in humans, 1930,31.

1930's Tolman, Purposive Behavior in Animals and Men, 1932.

Duncker, Zur Psychologie des produktiven Denkens, 1935.

Katona, Organizing and Memorizing, 1940

Luchins, Mechanization in Problem Solving, 1942.

1940's Duncker, On Problem Solving, 1945 (translation of Duncker, 1935).

Wertheimer, Productive Thinking, 1945.

Humphreys, Thinking, 1351.

Vinacke, The Psychology of Thinking, 1952.

Johnson, The Psychology of Thought and Judgment, 1955.

1950 's

Tanner \& Swets, Signal detection theory, 1954

Bruner, Goodnow \& Austin, A Study of Thinking, 1956.

Miller, The magical number seven, plus or minus two, 1956.

Chomsky, Syntactic Structures, 1957.

Broadbent. Perception and Communication, 1958.

Newell, Shaw \& Simon, Elements of a theory of human problem solving, 1958.

1960's Newell \& Simon, GPS: A program that simulates human thought, 1961.

Neisser, Cognitive Psychology, 1967.

1970's Estes (Ed.); Handbook of Learning and Cognition, 6 vol, 1975-78.

Johnson-Laird \& Wason (Ed.), Thinking, 1977.

Figure 2-1: Key events in one hundred years of the study of cognition. 


\subsection{Duncker}

Duncker was a Gestalt psychologist. Though the principle focus of the Gestalt work was in perception, both his mentors had worked on thinking: Kohler (1925) with the apes at Tenerife in 191417; Wertheimer (1945) with children in the classroom. Both efforts emphasized the understanding of relationships and the suddenness of insight. Both were justly famous. Kohler and Wertheimer were also two thirds of the Gestalt triumvirate; it follows that Duncker is a minor character on the stage of scientific history. Boring (1950) allots him just two sentences, followed immediately by the plaint that the mere listing of names is the bane of scientific histories. That did not keep Duncker's work from being extremely well known and giving impetus to much subsequent research.

Duncker is therefore part of what the textbooks called "the Gestalt theory of thinking". Gestalt psychology was a reaction to associationism and its behavioristic follow-on, and it never gave up its rhetoric of protest, even when, as Boring (1950) believed, it was "dying of success", its main points assimilated. However, in the study of higher mental processes it had the field somewhat to itself. The Behaviorists made only occasional forays into the area, engaging in their own reductionist rhetoric that thinking and problem solving are nothing but learning. Duncker's work bears strong kinship with others (Katona, 1940, Luchins, 1942, Maier, 1930, Maier, 1931) and this group in total occupied a prominent position in a non-prominent province of psychology. Duncker himself exhibits little of the Gestalt family's need to score on the Behaviorists. He finds good things in everybody, even Thorndike (1898) with his studies on cats in puzzle boxes, taken by most to be the hard rock on which the Behaviorists cast out meaningful insightful problem solving and replaced it with trial and error.

The selection of Duncker jumps in at midcentury, neglecting earlier work on thirking, though a few antecedents appear in the figure. But our need is for the cumulated knowledge about cognition as it existed just before the advent of information processing psychology, and Duncker suffices for this. How psychology arrived at Duncker is not our problem. ${ }^{3}$

\subsection{The Cognitive Revolution}

The post-fifties development is called both the information processing approach and the new cognitive psychology. It is perhaps soon to be called cognitive science, if the nascent movement to provide an umbrella name for linguistics, artificial intelligence and cognitive psychology takes firm root. Substantively, its underlying proposition is that theories of human voluntary behavior are to be sought in the realm of information processing systems. This is to be understood in the same sense that theories of macrophysics are to be sought in the realm of differential equation systems. There is

\footnotetext{
${ }^{3}$ The earlier period has been treated neatly by the Mandlers (Mandler \& Mandler, 1964) in Thinking: From Association to Gestath, which starts with Aristotie and ends with Duncker. In particular. they treat Otto Selz (1913, 1922) (1881-1943), the repeatedly rediscovered skeleton in cognitive psychology's closet (Humphrey, 1951. DeGroot. 1965), who understood essential elements of a processing explanation of thinking. and who could also have served for a centennial comparison.
} 
PAGE 6

a type of system -- called an information processing system -- that consists of memories and processors (also transducers, switches, controls, data operations and links, to be complete.) The system works on an internal medium of data structures, which represent things and situations. It performs operations on these representations to compute new representations and thereby generally manage its affairs in the world. This is an immense class of systems, all with a family resemblance -active, autonomous, rule-governed, limited structural and resource capacities, discrete, etc. The central agreement is that a human is this kind of a system, it being open and the object of empirical investigation to find out the particulars. Other major attempts to understand human nature can also be described in terms of the underlying system posited: the stimulus-response systems of behaviorism; the fields of Gestalt psychology; the hydraulic systems of Freudian psychology; the Markov systems of mathematical psychology.

The information processing revolution has in common this fundamental system view. It is otherwise importantly diverse, as the cluster of work in 1958 in Figure 2-1 indicates. Broadbent (1958) represents the line from control and communication engineering; it has focussed on working out the structure of the basic perceptual and processing mechanisms. Miller's paper on chunking and the limits of short term memory can be taken as part of that, as can the introduction of signal detection theory by Tanner \& Swets (1954). Our own work (Newell, Shaw \& Simon, 1958) can be taken to represent the line from programming and artificial intelligence (also to some extent from rational economics and decision theory). This is the symbolic level of information processing and is to be distinguished from the register-transfer level considered by Broadbent and company, exactly as software to hardware. These would be considered two entirely distinct system views -- except the study of computer systems has unified them (Bell \& Newell, 1971). The symbolic level, represented also by Bruner, Goodnow \& Austin (1956), provides the notions of plans, programs, procedures, and strategies. 1-ater, it provides the organization of knowledge in long term memory (Anderson \& Bower, 1973, Quillian, 1968). Chomsky (1957), represents the line from linguistics, with the view -- new to linguistics as well -- of rule-governed generative systems. This oversimplified picture does most violence here, since Chomskian linguistic contains strong elements of the structuralist tradition, which is distinct from the engineering and mathematical tradition I am taking as the central source for this cognitive revolution. ${ }^{4}$

As this diversity implies, the study of thinking and problem solving is only one component of cognitive psychology. It is not even the dominant component. Neisser's 1967 book, entitled Cognitive Psychology, crystallized for many the revolution and became its defining document. Yet, this book deals only with perception and basic processing, and ignores higher mental functions -- no problem

\footnotetext{
${ }^{4}$ This perspective places the source extraordinarily external to psychology. It conceals that the revolution was largely shaped by the psychologists themselves and merged with their internal traditions of experimentation and hypothesis-testing.
} 
solving, no concept formation, no planning. Duncker is not mentioned in it except for a perceptual experiment. This view is carried through Blumenthal's (1977) recent review of cognitive psychology, and onto an even more recent treatment that claims explicitly to lay out the cognitive paradigm (Lachman, Lachman \& Butterfield, 1979). Analyzing Duncker for what we have learned in cognition taps only one particular aspect of the total field.

This is enough historical context to consider what Duncker knew and how it compares with what we now know -- or think we know. There are three parts, corresponding to the three parts of Duncker's monograph: (1) The structure and dynamics of problem solving processes; (2) Insight, learning and simple finding; and (3) Fixedness of thought-material. Each part leads to a separate aspect of our general question. 
PAGE 8

\section{THE STRUCTURE AND DYNAMICS OF THE PROBLEM SOLVING PROCESS}

Duncker was clear about what he wanted to know: "How does the solution arise from the problem situation?" (p1). ${ }^{5}$ The question was not innocuous, however it may seem now. The dominant theory of thinking to that point, as defined by James, Dewey, Thorndike, Watson and others, was, roughly speaking, that the solution did not arise from the problem situation, but from trial and error or, at best, the experience of the problem solver.

The heart of the Gestalt position was that genuine problem solving behavior arises from the demands of the situation. Duncker in 1935 is rather non-polemical, but in 1926 (at age 23) he is more feisty:

As the point of departure for the present study 1 have chosen James' Chapter on 'Reasoning'. ... The gap which yawns in the great majority of theoretical or experimental studies upon thinking has nowhere else, as far as I know, been brought to such an extent of yawning as just there ... James is right [that reasoning proper is marked off from 'mere revery or associative sequence' by the extraction of the essential aspect out of a given fact], but now the fatal question arises: What makes the reasoner pick out just that fitting aspect ...? But we might as well let James himself raise the questions: 'To reason, then, we must be able to extract characters, not any characters, but the right characters. Here, then, is the difficulty ...' ... Thus we get the following list [after reviewing the answers of James, Dewey, Mach and Whewhell]: Interest in the interrelations of the facts, attentive scanning of the terrain, abstraction, imaginative activity, and -- opportune moment. The same yawning gap, carefully filled up with some general and formal attitudes." (Duncker, 1926, p642-647)

\subsection{What Duncker Knew}

Duncker had a well developed view of the main mechanisms by which problem solving occurs, much of it already in place in the 1926 paper. He used the first part of the 1935 monograph to lay out these mechanisms, working from thinking-aloud protocols of adults on a handful of different problems. The protocols have the flavor of demonstrations that make evident, rather than experiments that discriminate, much in the style of Wertheimer's book on productive thinking.

Let me sketch this model of the processing in my own terms, supported by quotations from Duncker.

1. The subject has a goal; the goal becomes a problem if it cannot be reached immediately by obvious actions.

"A problem arises when a living creature has a goal but does not know how this goal is to be reached. Whenever one cannot go from the given situation to the desired situation simply by action, then there has to be recourse to thinking. (By action we here understand the performance of obvious operations.)" (p1)

\footnotetext{
5 Throughout the paper, uniess otherwise indicated, alf quotations are to Duncker (1945) and all italics in the quotations occur in the original.
} 
2. Problem solving consists of a sequence of phases; each phase is a reformulation of the problem.

"... the solution of a new problem typically takes place in successive phases which (with the exception of the first phase) have, in retrospect the character of a solution and (with the exception of the last phase), in prospect, that a problem." (p18)

3. The intermediate phases (tentative solutions) embody the functiona/ value of the ultimate solution.

"The functional value of a solution is indispensable for the understanding of its being a solution. It is exactly what is called the sense, the principle or the point of the solution." (p4)

4. The sequence of phases constitutes a sequence of further specifications of the functional character of the solution.

"The final form of an individual solution is, in general, not reached by a single step from the original setting of the problem; on the contrary, the principle, the functional value of the solution, typically arises first and the final form of the solution in question develops only as this principle becomes successively more and more concrete." (p8)

5. There is search, which occurs in the space of functional specifications.

"It will be realized that, in the transition to phases in another line, the thoughtprocess may range more or less widely. Every such transition involves a return to an earlier phase of the problem; an earlier task is set anew; a new branching off from an old point in the family tree occurs. Sometimes a $S$ returns to the original setting of the problem, sometimes just to the immediately preceding phase." (p13)

6. The phases are under the control of general heuristic methods.

"We can therefore say that 'insistent' analyses of the situation, especially the endeavor to vary appropriate elements meaningfully sub specie of the goal, must belong to the essential nature of a solution through thinking. We may call such relatively general procedures, 'heuristic methods of thinking'." (p21)

"In a general thinking process, certain heuristic methods play a decisive role in mediating the genesis of successive solution-phases." (p24)

7. The solution depends on details fully specific to the problem situation.

"Thus every solution takes place, so to speak, on the concrete, specific substratum of its problem situation." (p20)

The key concept in this model is function. Its nature is clear enough in particular cases from the protocols of Duncker's subjects. For the X-ray problem there is the functional value: no contact between rays and healthy tissue; this is realized in the protocol statements "direct the rays by a natural approach", "expose by an operation", "protective wall" etc. A different functional value is: less intensity on the way, great intensity in the tumor; this shows in the protocol statement "concentration of diffuse rays in the tumor". Duncker gives trees of functions for two problems, 
aggregated from the data of many subjects, with increasingly specific functions as the tree branches down. These trees constitute the space in which subjects search for a solution.

Functions play a double role for Duncker. They are the crucial mediating construct in his theory, the central realization that comes to the subject when engaging in thinking. But functions are also crucial in the Gestalt protest against associationistic psychology. They represent the demands of the problem situation, being just what association theory of problem solving did not have (see quote on page 8 ). Though essentially non-polemical, the monograph retains a strong flavor of forward search as meaningless non-understanding behavior, whereas working with functions is meaningful, understanding behavior.

"I should like to name the first way the 'organic' one. Here from the 'function' ... arises the embodying material, the instrumental means. The second and opposite way is the 'mechanical' one. (p44)

"He who merely searches his memory for a 'solution of that such-and-such problem' may remain just as blind to the inner nature of the problem-situation before him as a person who, instead of thinking himself, refers the problem to an intelligent acquaintance or to an encyclopedia. Truly, these methods are not to be despised; for they have a certain heuristic value, and one can arrive at solutions in that fashion. But such problem-solving has little to do with thinking." (p20)

The first quote lays down the famous distinction between working backward as organic and working forward as mechanical. The second quote continues the same attitude, but significantly treats problem solving on its own terms. This open attitude of Dunckers leads (in my estimation) to his full-bodied model of problem solving. Here, for example is his characterization of Generate and Test:

"This suggestion of the functional value from below is even the rule in problems where a number of objects are offered to begin with, with the instruction to choose from among them an appropriate tool for such and such a purpose. Especially when only few objects are concerned, thinking will tend to proceed by looking things over, ie, it will test the given objects one after the other as to their applicability and no attempt will be made to conceive the appropriate functional value first." (p12)

This last quote leads to another key feature of Duncker's model, which is rather easy to overlook -the plethora of general heuristic methods. In fact, the first section appears to ramble, because Duncker, after introducing the basic notions of functions and successive reformulation phases, works through a large number of methods:

1. Suggestion from below: The materials of the problem suggest what needs to be done.

2. Learning from mistakes: Incorporation of the avoidance of the evil as an additional demand in finding a new line of approach.

3. Finding solutions through resonance: Finding a solution by a memory search with cues taken from the problem: "The problem is: ?Rb; $a R b$ exists in the thinker's experience; by reason of the partial correspondence with ?Rb, $a R b$ and therefore a are aroused." ( $p 19)$ 
4. Analysis of the situation as conflict: Asking "... Just why doesn't it work? or, What is the ground of the trouble (the conflict)?" (p21) as a means of finding what element of the situation to vary.

5. Analysis of the situation material: "What can I use?" (p21), as a deliberate question to analyze the situation. A special case is Explication of the premises in mathematical propositions.

6. Analysis of the goal: "What do I really want?", What can I dispense with?". "What does one do, in general, when one ...?" (p23), as questions to free the subject from fixations.

7. Par-force solutions: "In solving problems, one may very often be guided by natural reactions to forcible demands in the direction of the problem's goal ..." (p29).

8. That reminds me of ...: There are problems whose solution depends on the problem situation reminding the subject of some obscure fact or experience. But special cases are more directed, eg, "What theorems are there about such a thing ...?" (p37).

Duncker investigates each of these, usually with some data. Not all of these are well worked out total methods; many are more like the heuristic suggestions in Polya (1945). Yet he makes clear these are methods; eg, after a subject's explicit asking about theorems (above) he remarks "(An important heuristic method!)" (p37). Not all of these methods and heuristics are original with Duncker. He deals rather carefully with existing work. For instance, he understands Selz thoroughly and the method of solution through resonance is identified with Selz's method of determined means-abstraction. Or consider:

"Intelligent heuristic methods can be observed in the most primitive animal experiment. Thorndike, in his famous experiments on cats ..., could in this way establish that the 'tendency to pay attention to what it is doing' (instead of blind struggling) increased in the course of the experiment." (p24)

In sum, Duncker had a rather complete process model. At the center was the concept of function; but it had a diverse apparatus of methods. Comparison with others of the same era (Luchins, 1942, Katona, 1940, Wertheimer, 1945) reveals great agreement on the the notion of function as meaningful problem solving and the response to the demands of the situation -- namely, on the tenets of the Gestalt position. However, Duncker's total process model appears to be by far the most explicit of his contemporaries. It seems far from their major concerns.

There were limitations to the structure Duncker presented. He never attempted to characterize what a function is -- to describe the space of all functions. The common sense notion sufficed, illustrated by some demonstrated effects of problem structure and hints. The entire edifice is informal .- the quotes above being as precise as the monograph gets. Thus, whether the scheme is actually sufficient to account for any specific problem solving cannot be determined. In this respect, Duncker's use of protocols was coarse grained (about one statement every several minutes), capturing only the subject's major hypotheses about how to solve the problem (invariably a statement 
PAGE 12

of function).

\subsection{What We Now Know}

The modern state need not be set out beyond the earlier introduction. After all, we are -- for today, at least -- the moderns and it is our work. Instead, we can focus narrowly on particular features of modern work that illuminate advances beyond Duncker in areas directly related to his work.

We start with the model of means-ends problem solving provided by GPS (Newell \& Simon, 1961, Newell \& Simon, 1972), which can be epitomized by a trace of its typical behavior:

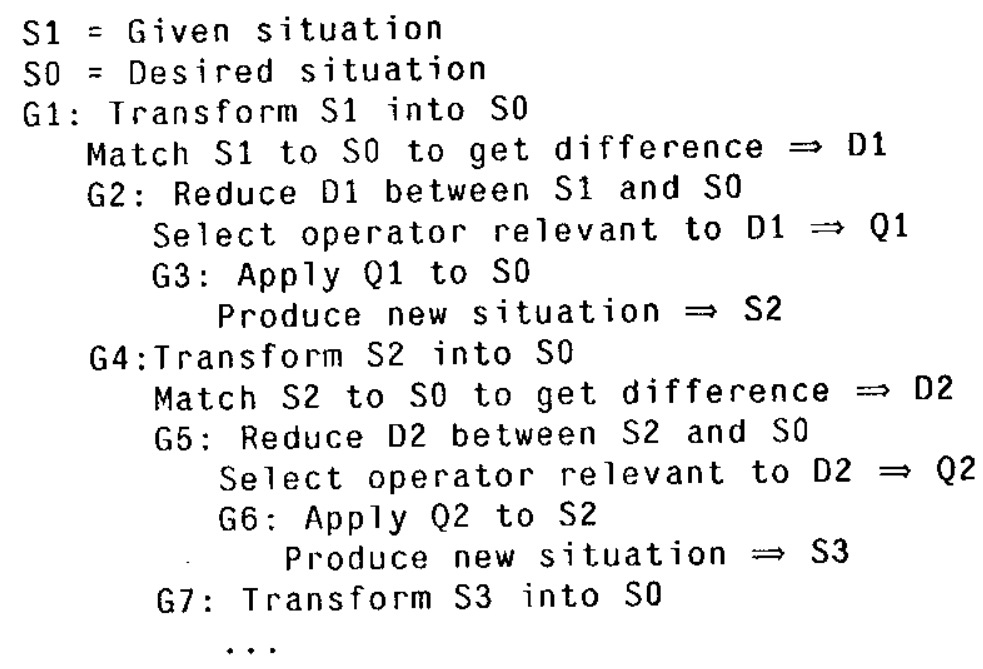

Comparing this with Duncker's scheme, reveals some obviously familiar elements: goals (the Gs); the repeated phases (at G1, G4, G7); and the general heuristic method that is used to generate the steps in the phases. In terms of general outline, GPS is just an instance of Duncker's scheme.

One thing not found in Duncker is indicated by the literals, the Gs, Ss, Ds and Qs. These are specific symbolic structures in a well defined symbol system, such as the programming language Lisp. Though the means-ends analysis scheme of GPS is often discussed in general terms, its usefulness derives from GPS having been demonstrated to be a sufficient scheme for the tasks to which it has been seriously applied. This is the gold-backing for the theory of means-ends analysis represented in GPS. it supports, for instance, comparison between GPS and behavior at a much finer level of detail (5-10 seconds) than Duncker used.

This may be summarized in two claimed advances over Duncker:

Advance: Theories of problem solving have been shown to be sufficient for problem solving.

Advance: An underlying symbol system has been posited in which cognition takes place. 
Consider now the role of the differences in the GPS scheme. Taking an early example from logic:

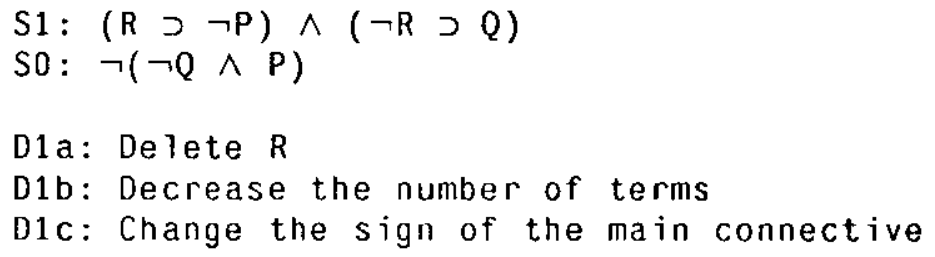

These difference terms -- delete term, decrease the number of terms, change connectives -- are clearly Duncker's functional values. They operate exactly as they should in Duncker's theory. They represent an analysis of the situation by the subject, characterizing what must be done and directing the search for something to accomplish that function, ie, an operator. They can be seen in the perceptual structure of the situation, exactly as required by Duncker's theory. What they provide that Duncker's treatment of functions does not is an actual explication of what the functional values are, how they arise and how they have their effects. This produces a third claim:

Advance: We now have an instance of a precise theory of functional value.

However, the theory of means-ends analysis embodied in GPS is not all gain. It is only an instance of a precise theory. Having the functions in the little logic task is far from having a general theory of functions. A trade-off invariably occurs when attaining adding precision in theoretical formulation. We can project from this what a general theory of functions might actually be like, but GPS hardly provides this, nor does other modern work.

The GPS related theory also falls shy of Duncker's scheme in being only a single method. As Duncker showed, there are many different general methods. Here the difficulty is merely with GPS, and not modern work generally, which has led to a ramified investigation of general problem solving methods and executive organizations. These are relatively content free, hence widely applicable. They organize activity, but do not provide strong direction, which must come from the concrete details of the task, which they are capable of absorbing. Here are some of them (Newe69H), though their details need not detain us:

Generate and Test: Generate in any way possible (eg, systematically or haphazardly) a sequence of candidate states, testing each for whether it is the desired state.

Heuristic Search: Apply heuristics to reject possible operators from the current state and to reject newly produced states; remember the states with untried operators in some systematic way (different schemes yield search strategies, such as depth first, breadth first, best first, progressive deepening).

Hill Climbing: Generate and apply operators from the current state; select one that produces a state with an improved evaluation and move to it. 
PAGE 14

Means-ends Analysis: Compare the current state with the desired state to detect any difference; use that difference to select an operator that reduces or eliminates it; otherwise proceed as in heuristic search.

Operator Subgoaling: If an operator cannot be applied to a current state, set up a subgoal to find a state in which the operator can be applied; otherwise proceed as in heuristic search or means-ends analysis.

Planning: Abstract from the present state (by processing only selected information throughout) and proceed to solve the simplified problem; use what is remembered of the path as a guide to solving the unabstracted problem.

The striking difference from Duncker's list is the emphasis on search. At the center of the modern theory of intelligence is the notion that all intelligent activity is carried on within the matrix of search, with devices for controlling or warding off incipient combinatorial explosion by bringing knowledge to bear. This runs directly counter to the basic Gestalt poșition in which search in all its various forms was the indicator of blind meaningless activity. That working forward (heuristic search, hill climbing and generate and test) and working backward (means-ends analysis) would be symmetrically considered, as opposed to being contrasted as mechanical to organic, runs against the Gestalt grain. This should be recorded as yet one more claim of what we have learned:

Advance: All intelligent activity is based in search.

We must be careful in this claim. First, Duncker genuinely makes room for search in his theory, separating himself thereby from the other Gestaltists. Second, though abating, controversy still exists in artificial intelligence over the role of general methods (often called uniform procedures) versus expert knowledge.

Finally, GPS appears to operate in a different space, namely the space of objects or situations. Sitting at a present situation, it characterizes its difference from the desired goal situation functionally, then uses that functional value to do something. On the contrary, in Duncker's theory the functional idea, once created, undergoes a series of refinements. Again, however, GPS-style meansends analysis is simply one mechanism of many. Much recent work has occurred on schemata and frames, structures that are more direct realizations of successive refinement and instantiation (Schank \& Ableson, 1977, Bobrow \& Winograd, 1977). These share the precision and concreteness of GPS. 


\section{INSIGHT, LEARNING AND SIMPLE FINDING}

Part Two of Duncker's monograph comprises three chapters: "On total insight or evidence"; "On learning and partial insight"; and "On solutions through resonance". It appears as a curious and obscure interlude between two readily comprehensible parts, the first on the general dynamics of problem solving (as we have seen) and the third on the special problem of functional fixity. Most commentators skip over these middle chapters, remarking on Duncker's grappling with philosophical problems:

"Duncker's work is not easy ... He hated any compromise with vague terms which give an appearance of knowledge while they actually hide problems. He simply would not let go until he knew the very anatomy of a concept. Thus in some chapters we find the author far within philosophy because the ramifications of insight would not become clear without that transgression." [Kohler, in the Introduction p. iv.]

"The philosopher will find especially interesting the account of the psychology of 'synthetic' insight in the Kantian sense, which is derived from Husserl's premises as contrasted with those of Kant." [Humphrey, 1951, p170]

Let us see how Duncker posed the problems for these chapters:

"As happens particularly with mathematical problems, the method of solution may consist, for example, in making appropriate deductions from the proposition or from the premises. But then the psychologist must still discover the psychological meaning of 'making deductions from', must discover how, from one fact, thinking actually brings about the intelligent transition to another, new fact. ... How does thinking succeed in reading off the cause from an effect, or the effect from a cause?" (p47)

Evidently, Duncker has left the realm of problem solving. That he has entered that of philosophy can be inferred from the following:

DEFINITIONS: A connection of two data a and b may be called 'totally intelligible', if it can be directly understood from $\mathrm{a}$ that, if $\mathrm{a}$ is valid. then $\mathrm{b}$ and precisely $\mathrm{b}$ is valid. (A connection is therefore 'unintelligible' to the extent to which it is to be 'accepted as mere fact'.) A connection may be called 'partially intelligible' ...

The definition given above of intelligibility has reference to a fundamental statement from Hume's 'Inquiry Concerning Human Understanding' (Sec. 7, Part 2): 'When any natural object or event is presented, it is impossible for us, by any sagacity or penetration, to discover, or even to conjecture, without experience, what event will result from it...' " (p47)

Although the commentators exude fair-mindedness, the inference seems inescapable that this part is of little central interest to psychology. Furthermore, insight was a notorious Gestalt concept. Any residual content of this second part is easily dismissed as flowing from general Gestalt attitudes and polemics:

"As prototype of entirely unintelligible connections we may cite one of those if-then relations which Thorndike imposed on his cats. If the cat licks itself, then the cage door opens, or if it presses on a certain knob, then the same happens. From the circumstance -. to be understood quite literally -- that a cat licks itself or presses on a certain known, it appears in no way intelligible that the cage door should open. (p48) 


\subsection{An Alte rnative View}

An alternative view of these three chapters is possible, which bears on what we have learned since Duncker. This view requires some preparation. Let me state it as an hypothesis, then state and explain the advance that 1 think has happened, before coming back to examine Duncker's work.

Hypothesis: Duncker is trying to discover the machine within which problem solving occurs.

The term machine is deliberate to make explicit the connection to the claimed advance:

Advance: Modern cognitive psychology has the concept of architecture, which is the physical machinery that realizes a symbolic system.

This concept of architecture needs expansion.

Computer simulation of problem solving has been important in modern cognitive psychology, but exactly what is going on has been less than clear to those involved. ${ }^{6}$ Some see it as a discipline to enforce operationalism. Some see it providing a language of processes. Some see the computer and its program as the computational means for producing the step by step consequences of a theory stated mathematically, as in computer simulation generally. Some see the program itself as a theory.

The confusion has been compounded, because simulations are written in programming languages. Clearly not psychological theories in general, some programming languages, especially the list processing languages, appear to have psychological import. However, no matter what language is used, much of any complex simulation program is detailed housekeeping required just to make the program complete enough to run. Moreover, whether intrinsically or because of this extra detail, simulation programs are big, complex, hard to understand and hard to communicate (Reitman, 1965).

Clarity seems to be emerging (Newell, 1973, Pylyshyn, 1980). As noted earlier, modern cognition asserts that humans have symbol systems (Lachman, Lachman \& Butterfield, 1979, Newelf, 1980), ie, a collection of mental entities called symbols, whose tokens occur in symbolic expressions or structures. These are the carriers of information, stored in memory and the objects of processing. This symbolic level corresponds to the programming level in computers.

Symbol systems must, of course, be realized by some physical system. It has become customary in computer science to refer to this physical structure as the architecture, ie, an architecture supports a symbol system. Different architectures yield different flavors of symbol systems. Though these may differ radically in many ways, they will all have the properties we associate with programming languages -- ie, what is common to Fortran, Lisp, Snobol, Algol68, Pascal, myriad assembly languages, etc. To draw the obvious conclusion: if the human has a symbol system, the human has an architecture that supports that symbol system. Within that architecture, programs (ie, symbolic

\footnotetext{
${ }^{6}$ Newell (1970) has an extended discussion of the variety of these views with appropriate references and quotations.
} 
expressions that designate the human's own mental processes) correspond to psychologically meaningful actions and thoughts.

If a simulation were programmed on a computer that had the same architecture as the human, all its properties would be of psychological interest and all the details of the programs would be psychologically relevant. The role of simulation would become transparent. The architecture plus the program is a theory of the human cognitive system. Such a situation would be essentially different from using a computer (ie, an architecture plus a programming language) to simulate (say) a business inventory system. This latter is both possible and useful, but the aspects relevant to the inventory system must be declared (by describing the model of the inventory system in independent terms and thinking of the program as simply implementing the computations dictated by the model).

We can now turn back to Duncker. He had seen, as reflected in part I, a variety of high level cognitive activity. He sought the grounds on which this occurred. He certainly did not have the notion of a symbolic processor (this was the early thirties). Rather, he had the Gestalt notions of organization, insight, and field (the physical substrate). Yet in these chapters he takes up a series of issues which seem quite close to trying to specify the nature of the architecture -- of the underlying processing system. There is space to deal only with a single example, though it is a fascinating one.

\subsection{A Computational Model of Insight}

The example concerns the nature of insight. Duncker took insight as occurring when a functional value was seen as following from the givens of the problem situation. For example, a subject sees that no contact between rays and healthy tissue is demanded by the $x$-ray problem.

The example Duncker worked out in most detail was:

From $a>b$ and $b>c$ to understand that $a>c$.

The ingredients of his solution are laid out in Figure 4-1. There is a data structure, which is a model in the formal (model-theoretic) sense of the term in modern logic (Addison, Henkin \& Tarski, 1972). The givens are interpreted in the model by means of constructions (write operations). The conclusion is extracted from the model by a read operation, ie, by seeing what is now true in the model. The mind's eye watches over everything as the executive control. Let the model be an internal line; then $a>b>c$ is layed off internally as three points and the eye can see (read-off) that $a>c$, because it is now true in the model.

This technique of computing is not familiar, but it does occur and can be quite effective. For instance, IBM cards can be decoded by writing them out to memory as 12 rows of 80 bits (as they come in from the card reader) and then reading them back in as 80 columns of 12 bits, which can be interpreted as numbers. Our immediate concern is not the scheme per se, but how Duncker saw it. 


\section{MONITORING EYE}
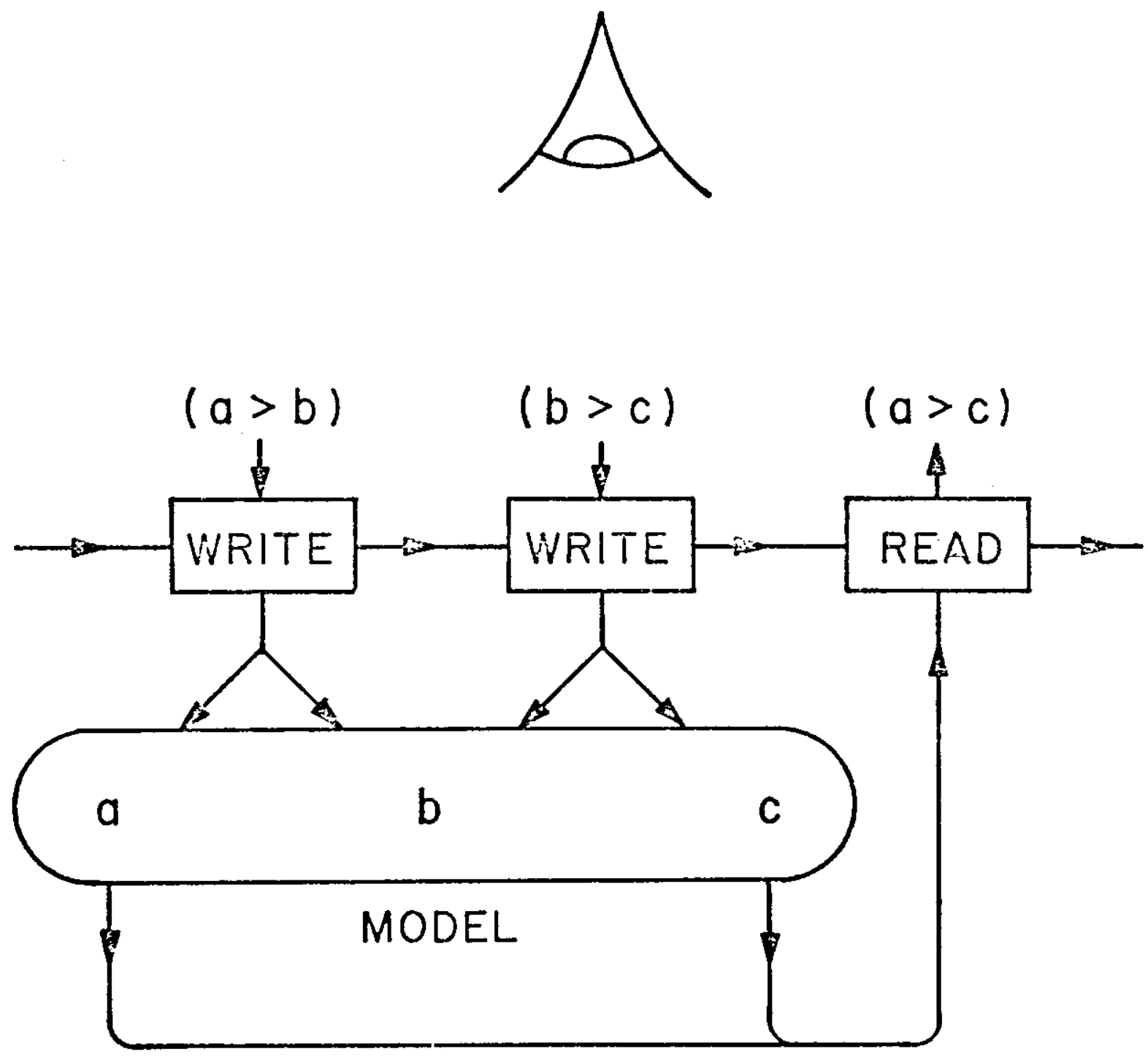

Figu re 4-1: Duncker's computational model of insight. 
Here is how Duncker describes the operation of insight:

"How about the example: 'From $a>b>c$ it follows that $a>c$ ?' I can demonstrate the meaning of 'greater' on all kinds of pairs of objects. With the help of the concept so obtained, a clear 'paradigmatic' situation: 'a greater than $b$ and $b$ greater than $c$ ', can be constructed. From the situation so constructed, the fact: 'a greater than $c$ ' may now be read off. Yet -. and this is the important point -- this fact was not needed in the construction of the situation, the 'foundation' from which it is now being read off." $(\mathrm{p} 49)$

Duncker makes clear he knows the standard way of applying the transitive law as a rule -- and that he intends something different:

"For the modern mathematician, the straight line is that entity -- originally undefined -which receives definition from the axioms about it, nothing more. And the relation: "greater than' acquires its transitiveness in mathematics merely by logical deduction from certain postulates, from the axioms about the relations: 'between' and 'congruent'." ( $p 50)$

"There is no objection to this procedure. The mathematician and logician may proceed thus. As a matter of fact, mathematics and logic would 'function' even if all principles were nothing but postulates. In short, 'postulation' and 'evident following from' are equivalent in respect to their logical achievements. ... However, even though certain if-then relations may be treated as mere postulates, they can also be seen in a different light. Perhaps this other conception is irrelevant to the purely logical structure of mathematics. It nevertheless corresponds to actual facts in thinking." (p51)

Construction and reading-off is not simply a way of stating that some process takes inputs and delivers outputs:

"Now, one might be tempted to generalize from this [the example] and to say: 'Synthetic evidence [ie, this particular subspecies of insight] obviously consists in the fact that the new characteristics resulting from a new structuring of given elements are read off from these elements'. But with this one would have lost again the specific meaning of evidence and of 'insight'. For if one properly combines pure hydrogen and pure oxygen ... and if one reads off the result: the explosion and the formation of water, then to be sure, something very important is read off, but certainly no synthetic evidence. ...

In short, synthetic insight cannot consist simply in the fact that the result of a new organization is read off. In order to be comprehensible as an instance of synthetic evidence, the example ... must therefore be otherwise interpreted. ... But this means that it remains identical in the respect in which it serves as 'foundation' for the two successive functions." (p54)

"If this condition of identify be given sufficient attention, there will be no danger that the subject regard something as intelligible just because, in the moment of inspection, it happens to be apparent. Suppose, in the moment of reading off from: $a>b$ and $b>c$, the $a$ were suddenly and maliciously to shrink (or turn red). Surely, under these circumstances the subject would not be doomed unsuspectingly to regard as evident from the premises that a must be less than $c$ (or redder than $c$ )." ...

Synthetic evidence is possible through the fact that from a situation given in a certain structuring and characterized by certain functions (aspects), without any change in essential foundations new functions (aspects) may be read off by virtue of new organizations." (p54) 
Thus, the model must remain under computational inspection so the subject can know that the result being read out of the model is due only to what was read into the model. This is the essential -and computationally novel -- function of the mind's eye.

Duncker understands that just having a model for an inference does not establish its validity:

"How is the generality of a given insight possible, although each time such evidence results from only one paradigm [model]? ... obviously no more is necessary than that, in employing a concept -- e.g., the concept 'greater than' -- I am able to distinguish the essential from the non-essential characteristics of an object. Thus I must distinguish the characteristic: 'greater than' from the characteristic: 'about 2.5 meters greater than', more particularly from the entirely non-essential green-ness of the tree which is greater than the bush. I can in fact do this, as truly as I can conceive and employ concepts at all. Consequently, I can also recognize, during inspection, what characteristics of the foundation enter into the given evidence present and what others do not." (p55)

"We shall call a situation 'paradigmatic' if it is constructed for the mind's eye by the exclusive use of the concepts expressly contained in the premises." ( $p 49)$

This computational scheme does not produce necessarily valid inferences, but Duncker is not claiming such (though he makes no explicit disavowal). He is laying out the computational steps that lead the subject to see new information as following necessarily from given premises. But the subject can be fooled; ie, understanding can be mistaken.

This is as far as we can take this example. The evidence seems compelling that Duncker was taking an essentially computational view. Insight for Duncker was a particular set of cognitive operations that cooperated to establish conditions under which understanding would accrue. The set of conditions are genuinely ingenious. Though the matter cannot be pursued here, their investigation would be an excellent research bet.

\subsection{Other Mechanisms}

There is no space for other examples in sufficient detail to be convincing. Chapter 6 contains an extensive characterization of the process of memory search, which is clearly aimed at understanding another primitive operation of the architecture. Duncker seeks to establish that a search model is set up by understanding the task instructions, so a stage of search formulation occurs prior to the search itself. Then the search proceeds by a series of perusals of the search field, these perusals being according to the nature of the field, eg, geographically (in the mind's eye) if looking for cities, etc. The approach is similar to Shiffrin's (1970) model of long term memory search (probably the best modern treatment), though without any of the mathematical apparatus, precision or data. This chapter adds a good second data point to the claim that Duncker was attempting to formulate the architecture.

Chapter 5 is less rewarding. Duncker focusses on the nature of the world rather than the human

processor. What structure must it have to suggest clues about causal relations. He assumes the 
human is built to be a coincidence detector, but doesn't pursue the matter on the architecture side.

\subsection{Limitations}

To summarize the point: Duncker was attempting to pose the question of what elementary information processes need to exist for the problem solver to reason. He was not saying that some special and unanalyzable process called insight occurred. On the contrary, insight was for him a special computational device where, having encoded the knowledge, the computation could be made by recognition (accessing) under special conditions, which themselves could be enforced by recognition. He did not concern himself exclusively with insight, though we did not establish this so clearly. He recognized the appropriate role of associations as well as the operation of searches of long term memory.

Such questions are now more easily put. The proposal to explore the architecture of the human mind is a coherent research proposal. We do not know how clear Duncker was about his own project; we certainly know that he did not communicate this to the world, neither to the mainline world of behavioristic psychology, from which he was distant, nor to the Gestalt world, of which he was a part - nor even to the information processing world of 1958 , if my own reading then is an indicator.

There are limits to anticipation. Though Duncker was led to take mental operations seriously, he was not led to deal with the control structure, ie, with the overall operating structure of the mind. There was still a subject whose inner eye watched the computation occurring in inner space, to become convinced and attain understanding if it had witnessed all the conditions satisfied.

The lack of concern for control structure and for reduction to mechanism can also be clearly seen in Duncker's treatment of general heuristic methods. They are formulated in natural language (eg, "analyze the goal") and it is simply assumed that we understand how a human could behave in such a way. Though he came to ask reductionistic questions -- ie, what mechanisms underly the humans ability to problem solving meaningfully -- he did not seem to be aware of the need at this level.

In sum, there was still the homunculus. In this respect we are much better off:

Advance: The homunculus can (on occasion) be banished.

With computer simulation has come a research style in which the homunculus can finally be exorcised. GPS has no homunculus, nor do many other simulation programs. However, the advance remains limited, for even a casual perusal of the modern literature of cognitive processes shows the homunculus well in evidence in many areas.

Duncker was also not sensitive to computational issues of representation. What sort of data structures his functions could be was not something that he could easily have addressed. However, 
PAGE 22

he does not quite completely ignore it. In discussing the nature of experience in Chapter 5, he addresses directly what is learned, and makes the following remark, which is clearly pertinent to recent discussions on representation:

"'Experiences' are not in general crystallized in statements, but in attributes of objects. ... ground-consequence experiences or end-means experiences are embodied in 'functional characters' of the objects themselves. The hammer is something for driving nails, the bench is something for resting on." (p73) 


\section{FIXEDNESS OF THOUGHT-MATERIAL}

The last part of Duncker's monograph concerns finding materials that satisfy the functions required by a problem. It flows directly from Duncker's theory of problem solving, which puts the functional characterization of a problem as the decisive cognitive step. The focus is on a particular phenomena, functional fixity, which causes subjects to fail, even though actively looking. Here is the situation:

The subject is looking for an object to perform a new function, $F_{\text {new }}$.

An object exists in the situation that could provide $F_{\text {new }}$.

This object is already characterized as providing a different function, $F_{\text {old }}$.

This decreases the chance of finding the object for $F_{\text {new. }}$.

In Duncker's language: $F_{\text {old }}$ becomes fixed to the object, so that the subject does not see it as available for $\mathrm{F}_{\text {new. }}$. Such fixation is a priori surprising, because functions are not objective properties of an object, but constructs of the subject.

This is the smallest part of the monograph -- 26 pages versus 45 and 34 respectively for the first two parts. Yet it had by far the largest impact. Functional fixity generated one of the major streams of research in problem solving until the shift in the mid-fifties to information processing. Part I of the monograph was included in the descriptions in textbooks and reviews of the nature of problem solving and thought. Part II was dismissed, either as another exposition of the Gestalt position on insight or as a philosophical excursion. But Part lll generated research. In a theory-less experimental science, the ability to capture the experimenter hours of your colleagues ultimately defines influence. Thus, we need to understand what Duncker discovered in this third part, why the psychology of midcentury took it up so vigorously, and how our own modern position on this phenomena compares.

\subsection{What Duncker Knew}

Duncker's style of investigation in each of the three parts was quite distinct. In this last part, having focussed on the phenomena of fixedness, he performed many small experiments to reveal many factors that affect the amount of fixedness that a subject shows. An abbreviated (somewhat cryptic) list gives the flavor. Implicit in each factor is a comparison of two experimental situations.

1. The object is characterized by a different function $\left(F_{\text {old }}\right.$ not the same as $\left.F_{\text {new }}\right)$. [More] (Restating the basic phenomenon)

2. The object is considered as being used only for the different function (ie, for $F_{\text {old }}$ ). [More]

3. The new function $\left(F_{\text {new }}\right)$ is considered to be uniquely satisfied by a different kind of object. [More]

4. The new function is less obvious perceptually (pregnant) in the object. [More]

5. The functions $\left(F_{\text {new }}\right.$ and $\left.F_{\text {old }}\right)$ are quite dissimilar types (heterogeneous). [More] 
6. The functions $\left(F_{\text {new }}\right.$ and $F_{\text {old }}$ ) are quite similar types (homogeneous). [Less]

7. The object is called to attention somehow (ie, in ways not related to its function). [Less]

8. The object is central to the task (and $\mathrm{F}_{\text {old }}$ may be strong). [Less]

Duncker had no theory of functional fixity, beyond that implicit in the metaphor of fixing plus some notion that $F_{\text {old }}$ interferes with $F_{\text {new. }}$. This leads him to be surprised about items 5 and 6 (the closer two items, the more they should interfere) and 8 (the more central the object the stronger it should bind its function).

\subsection{Why Psychology took up Functional Fixity}

Functional fixity did not stand by itself as an isolated experimental phenomena. It became included in the topic of set, the general factor in the organism that prepares it to respond or perceive the environment in a given way, enhancing or inhibiting responsiveness as the situation agrees or not with the preparation. Set was a general psychological phenomena, but within problem solving, the work of three people dominated its investigation: Duncker on functional fixity; N. R. F. Maier (1930, 1931) on direction in problem solving (recall the two-string task); and Luchins (1942) on the Einstellung effect (recall the water-jug task). As one indication of its importance, the 1955 Annual Review of Psychology discussion on thinking and problem solving (Taylor \& McNemar, 1955) devotes a third of its pages to set, with major subsections on Einstellung and functional fixity.

No point is served by reciting what was learned by others about set in general or functional fixity in particular. There followed an enumeration of independent variables that affected the formation of set of one kind or another, with experimental demonstrations of which way the effects went. I have not done a literature count; my estimate is that the whole tradition produced a few hundred experimental variations. It is not an exciting and integrated literature. The results seem, at this remove, just like so many facts: anxiety increases set; pressure increases set; time dissipates set; individuals differ.

Little increase occurred in understanding theoretically what processes caused set. This simply reflects the general distance of the forties and fifties from an adequate and accepted model of processing, the area being no wise special vis a vis the larger Zeitgeist of experimental psychology. This provides a direct explanation of why psychology chose this third part of Duncker, leaving all the rest either unattended or simply grist for overviews and reviews. Duncker's own approach in this third part meshed exactly with the experimental attitudes and capabilities of the times, and his findings were provocative enough to provide issues to pursue.

The story cannot end quite here, as if just fitting into the paradigm style were enough. As the concordance of the issues by Maier, Luchins and Duncker indicates, something in the issue of set 
was especially exciting and provocative to the times. Perhaps it was the notion of a hidden factor, not accessible to consciousness or introspection, that made tasks difficult or gave them direction. Certainly many of the issues that fascinated psychology in this period have a similar flavor -- latent learning, the new look in perception, unawareness in concept formation. However, tracking this down would take us not only beyond Duncker, but beyond the spirit of the Monograph, which despite the third part, is strongly focussed on process.

\subsection{The Position of Modern Cognition}

Almost no studies of functional fixity (or other phenomena of set) occur any more; and haven't since the early sixties, which is to say, since the cognitive revolution. The research did not stop because nothing more could be learned about functional fixity, Einstellung and the rest. To modern view, not much had been learned. The research simply ceased, because modern cognitive psychology shifted its concerns to internal memory structure and problem solving processes. Functional fixity research appeared devoid of either.

Duncker did not develop a process model of functional fixity. It is easy enough to do, given our current knowledge. Here is a simple model from which all of Duncker's phenomena follow.

To find an object to perform a (new) function, the subject must engage in a two step process:

1. A recognitional scan to identify candidates.

2. An evaluation of the resulting candidates for appropriateness.

The subject has no way to enumerate the items in a task environment and evaluate them all. The environment is always so rich that the first stage must be recognitional. There is a large dependency in this first stage on both the surface aspects of the task and on aspects that can be selected a priori, ie, without knowledge of the objects to be found. The subject will miss objects that cannot be acquired in this fashion. Once acquired, for whatever reason, the evaluation of whether an object can perform a function goes relatively easily.

The ability to generate reasonable theoretically based explanations can be taken as one more advance.

It is tempting to invoke the Kuhnian model (Kuhn, 1962) to explain the failure of modern cognition to pursue functional fixity -- the paradigm shift, scientific elites talking past one another, and so on. In part the story fits, especially the shift to new questions and derivations from different models. However, in one important way it won't do. The underlying role of functions -- how they affect the course of reasoning and the difficulty of problems -- is as important for the modern theory of cognition as for Duncker. Duncker made a good case for the contribution of functional fixity to the difficulty of problems. Though we may be cavalier about a processing theory of functional fixity, as just one more phenomena to be modeled, we are every bit as concerned with why problems are difficult and what can be done about it. The modern theory of problem solving has not made great strides in predicting 
PAGE 26

why problems are difficult. Functional fixity remains an item on our agenda, though there seems no way to predict when it will capture our attention again. 


\section{CONCLUSION}

Our exploration of Duncker on problem solving is complete. Where do we stand in sum? Duncker's 1935 monograph itself stood almost exactly half way between Wundt and the present celebration, though it was not until the fifties -- almost four-fifths of the way -- that the field moved substantially beyond it. However, we must separate what Duncker himself knew from what the field as a whole knew.

Duncker interpreted everything through Gestalt spectacles. To first order what he says is familiar: task demands, functions, blind solving, understanding, insight. Yet, as an acute observer of the actual problem solving behavior of his subjects, in his understanding of process he moved beyond anything to be found in the other Gestaltists. He understood much that we now see in modern information processing terms: the structure of general heuristic methods, means-ends analysis, search. He was even reaching for how to characterize the underlying processing structure -- the architecture.

Turning to the field at large in Duncker's era, concern with processing structure and underlying architecture is all but non-existent. In its stead is experimental variation of independent variables, the modus viviandi of experimental psychology. It is no surprise that the field took from Duncker what was amenable to experimental variational thinking. Facts about functional fixity could be accumulated indefinitely without making substantial progress on the mechanisms that generate it or its role in the larger scheme of cognitive life.

Contrasting our own state in problem solving with that of Duncker himself, the advances we have claimed seem primarily of the form "we now have more precise models". That might seem a modest claim. I do not think so. Casting the problem of cognition within a world of mechanism generated the conceptual storm of the fifties and the waves that swept all before them.

It is not enough just to have a notion of mechanism. The Gestaltists had such a notion -. the physical field. So too did Freudian psychology -- the psychic energy in a hydraulic like system. From our present vantage point, these notions are simply not the right mechanism. The human is a processor of information: he is not like a physical field; he is not like a libido conservative energy system. Ground can be gained (and was) working under the aegis of these other metaphors. However, they eventually come to hinder more than they help.

Some feel the notion of information processing to be simply another metaphor, like that of field or psychic energy. Only the future can tell. Though it does not seem so to me, spelling out the grounds of that belief is not the business of this paper (Newell, 1980). In all events, the notion of symbolic information processing has provided us 'with new and striking high water marks for the detailed 
PAGE 28

understanding of human cognition. Succeeding reformulations will have to move up to still higher ground. That can only be to the great advantage of us all.

Re-viewing this excursion into Karl Duncker, performed twenty years late, I find myself pleased and also confirmed in my assessment (both rational and emotional) about the course of modern cognitive psychology and the advances it has made. More important, I have found things in Duncker I did not find or understand twenty years ago. These seem central to his own research -- therefore not of my own construction -- and also consistent with what modern cognitive psychology is trying to do and understand. Could anything more be asked from a modest historical exercise? Yes, perhaps one more thing: That we not forget how far Duncker had come in his understanding. 
PAGE 29

\section{REFERENCES}

Addision, J. W., Henkin, L. \& Tarski, A. (Eds.). The Theory of Models. Amsterdam: North Holland 1972.

Anderson, J. R., and Bower, G. Human Associative Memory. Hillsdale, N.J.: Erlbaum 1973.

Bell, C. G. \& Newell, A. Computer Structures: Readings and Examples. New York: McGraw-Hill 1971.

Blumenthal, A. L. . The Processes of Cognition. Englewood Height, N.J.: Prentice-Hall 1977.

Bobrow, D. G. \& Winograd, T. An overview of KRL, a knowledge representation language. Cognitive Science, 1977, 1, 3-46.

Boring, E. W. History of Experimental Psychology. New York: Appleton-Century-Crofts 1950.

Broadbent, D. M. Perception and Communication. London: Pergamon 1958.

Bruner, J. S., Goodnow, J. J. and Austin, G. A. A Study in Thinking. New York: Wiley 1956.

Chomsky, N. Syntactic Structures. The Hague: Mouton 1957.

DeGroot, A. D. Thought and Choice in Chess. The Hague: Mouton 1965.

Dewey, J. How We Think. Boston: Heath 1910.

Duncker, K. A qualitative (experimental and theoretical) study of productive thinking (solving of comprehensible problems). Pedagogical Seminary, 1926, 33, 642-708.

Duncker, K. Zur Psychologie des produktiven Denkens. Berlin: Springer 1935.

Duncker, K. On Problem Solving. Psychological Monographs, 1945, 58, 1-113. Whole No. 270.

Estes, W. (Ed). Handbook of Learning and Cognition, vol 1-6. Hillsdale, NJ: Erlbaum 1975. (1975-78).

Humphrey, G. and Coxon, R. V. The Chemistry of Thinking. London: Pergammon 1963.

Humphrey, G. Thinking. Oxford: Oxford University 1951.

James, W. Principles of Psychology. New York: Holt 1890.

Johnson-Laird, P. N. \& Wason, P. C., (Eds.). Thinking. London: Cambridge University Press 1977.

Johnson, D. M. The Psychology of Thought and Judgment. New York: Harper 1955.

Johnson, D. M. A systematic introduction to the Psychology of Thinking. New York: Harper \& Row 1972.

Katona, G. Organizing and Memorizing. New York: Columbia University Press 1940.

Kohler, W. The Mentality of Apes. London: Routledge and Kegan Paul 1925.

Kuhn, T. S. The Structure of Scientific Revolutions. Chicago: Chicago University Press 1962.

Lachman, R., Lachman, J. L. and Butterfield, E. C. Cognitive Psychology and Information Processing: An introduction. Hillsdale, N.J.: Erlbaum 1979. 
PAGE 30

Luchins, A.S. Mechanization in problem solving: The effect of Einstellung. Psychological Monographs, 1942, 54, 1-95. Whole No. 248.

Maier, N. R. F. Reasoning in humans, I: On direction. Journal Comparative Psychology, 1930, 10, 115143.

Maier, N. R. F. Reasoning in humans, II: The solution of a problem and its appearance in consciousness. Journal Comparative Psychology, 1931, 12, 181-194.

Mandler, J. \& Mandler, G. Thinking: From association to Gestalt. New York: Wiley 1964.

Miller, G. A. The magic number seven, plus or minus two: Some limits on our capacity for processing information. Psychological Review, 1956, 63, 81-97.

Miller, G. A. A Very Personal History. Talk to Cognitive Science Workshop, MIT, 1 June 79.

Neisser, U. Cognitive Psychology. New York: Appleton-Century-Crofts 1967.

Newell, A. \& Simon, H. A. GPS, a program that simulates human thought. In Billing, H. (Ed.), Lernende Automaten, Munich: Oldenbourg, 1961. (Reprinted in Feigenbaum, E. and Feldman, J. (eds.), Computers and Thought, McGraw-Hill, 1963).

Newell, A. \& Simon, H. A. Human Problem Solving. Englewood Cliffs: Prentice-Hall 1972.

Newell, A., Shaw, J. C. \& Simon, H. A. Preliminary Description of General Problem Solving Program-I (GPS-1). Technical Report, Carnegie institute of Technology, December 1957.

Newell, A., Shaw, J. C. \& Simon, H. A. Elements of a theory of human problem solving. Psychological Review, 1958, 65, 151-166.

Newell, A., Shaw, J. C., \& Simon, H. A. Report on a general problem-solving program for a computer. In Information Processing: Proceedings of the Irternational Conference on Information Processing, Paris: UNESCO, 1960.

Newell, A. Remarks on the relationship between artificial intelligence and cognitive psychology. In Banerji, R. \& Mesarovic, J. D. (Ed.), Theoretical Approaches to Non-Numerical Problem Solving, New York: Springer-Verlag, 1970.

Newell, A. Production systems: Models of control structures. In Chase, W. C. (Ed.), Visual Information Processing, New York: Academic Press, 1973.

Newell, A. Physical symbol systems. Cognitive Science, 1980, 4, 135-183.

Polya, G. How to Solve it. Princeton, N.J.: Princeton University 1945.

Pylyshyn, Z.W. Computation and cognition: Issues in the foundations of cognitive science. The Behavior and Brain Sciences, 1980, 3, 111-169.

Quillian, M. R. Semantic memory. In Minsky, M. (Ed.), Semantic Information Processing, Cambridge, Mass.: MIT Press, 1968.

Reitman, W. Cognition and Thought. New York: Wiley 1965.

Schank, R. \& Ableson, R. Scripts, Plans, Goals and Understanding. Hillsdale, N.J.: Lawrence Erlbaum 1977. 
PAGE 31

Selz, O. Uber die Gesetze des geordneten Denkverlaufs. Stuttgart: Spemann 1913.

Selz, O. Zur Psychologie des produktiven Denkens und des Irrtums. Bonn: F. Cohen 1922.

Shiffrin, R. M. Memory search. In Norman, D. A. (Ed.), Models of Human Memory, New York: Academic, 1970.

Tanner, J.P. Jr. \& Swets, J. A. A decision-making theory of visual detection. Psychological Review, $1954,61,401-409$.

Taylor, D. W. \& McNemar, O. W. Problem solving and thinking. Annual Review of Psychology, 1955, 6, 455-482.

Thorndike, E. L. Animal intelligence. Psychological Monograph, 1898, 2, .

Tolman, E. C. Purposive Behavior in Animal and Men. New York: Appleton-Century-Crofts 1932.

Vinacke, W. E. Psychology of Thinking. New York: McGraw-Hill 1952.

Vinacke, W. E. Psychology of Thinking, 2nd Ed. New York: McGraw-Hill 1974.

Wertheimer, M. Productive Thinking. New York: Harper 1945. 